\title{
Health Consequences to Immigrant Family Caregivers in Canada
}

\author{
Juhee Vajracharya Suwal \\ Cancer Surveillance \\ Surveillance and Health Status Assessment \\ Population and Public Health \\ Alberta Health Services \\ Edmonton, Alberta, Canada \\ E-mail: jsuwal@ualberta.ca
}

\begin{abstract}
This study revisited the "double jeopardy" hypothesis in terms of the health of immigrant family caregivers. It also investigated the effect of "reciprocity" (feeling of giving back something) on the health of family caregivers. The General Social Survey 2002 Cycle 16 data were analyzed using $\chi^{2}$-test and Logistic regressions. About $16 \%$ of immigrants and $13.6 \%$ of non-immigrants said that their health was negatively affected as a result of caregiving. Immigrant family caregivers were three times more likely than non-immigrants to report a health consequence. Reciprocity played a big role in this outcome. Given the fact that an increasing number of culturally diverse immigrants enter Canada every year and that the immigrant population is aging, more caregivers will be in demand. Policy makers need to find ways to keep immigrant caregivers healthy so that quality care can be given to immigrant older adults and also for maintaining an overall healthy Canada.
\end{abstract}

Key Words: Health consequences, immigrants, caregivers, older adults, General Social Survey Cycle 16, logistic regression

CSP 2010, 37.1-2: 107-124 


\section{Résumé}

Cette étude réexamine l'hypothèse de «non bis in idem» dans le contexte de la santé des aidantes et aidants membres de familles immigrantes. Elle étudie aussi l'effet de "réciprocité» (le sentiment de rendre quelque chose) sur la santé des aidantes et aidants membres de la famille. Les données de l'Enquête sociale générale 2002, cycle 16 ont été analysées à l'aide du test du $\chi^{2}$ et de régressions

logistiques. À peu près $16 \%$ des immigrants et $13.6 \%$ des non-immigrantes ont reporté que leur santé avait été négativement affectée par leur dispensation de soins. Les aidantes et aidants membres de familles immigrantes avaient trois fois plus de chance de reporter une conséquence sur leur santé que ceux des familles non-immigrantes. La réciprocité jouait un rôle important dans ce résultat. Quand on considère qu'un nombre croissant d'immigrants issus de cultures diverses entre au Canada chaque année et que la population immigrante vieillit, il est clair que plus en plus d'aidantes et d'aidants membres de familles vont être requis à l'avenir. Il est important pour les décideurs publiques de trouver comment garder les aidantes et aidants membres de familles immigrantes en bonne santé pour que des soins de qualité puissent être offerts aux personnes immigrantes âgées et aussi pour maintenir un haut niveau de santé générale au Canada.

Mots-clés : Effets sur la santé, immigrants, aidants et aidants naturels, personnes âgées, Enquête sociale générale cycle 16

\section{Introduction}

Family caregivers paying an invisible price of non-economic consequences as a result of caregiving is well acknowledged in the literature (Fast, Williamson and Keating 1999; Fast and Keating 2001; Victorian Order of Nurses 2005). ${ }^{1}$ About one-third of family caregivers are found to suffer from ailing health (NavaieWaliser, Feldman, Gould, Levine, Kuerbis and Donelan 2002). As the demand of caregiving increases, the health of family caregivers deteriorates (Cox and Monk 1993; Hennessy and John 1996; Fast et al. 1999; Policy Forum on Unpaid Caregiving 2003), especially if care is provided to older adults with dementia (Campbell, Bruhn and Lilley 1998; Pinquart and Sörensen 2003; Kosmala and Kloszewska 2004). The main focus of this study is to investigate the impact of informal caregiving on the health of immigrant caregivers.

CSP 2010, 37.1-2: 107-124 
In spite of immigrants accounting for $18.4 \%$ of the population in the 2001 census (Statistics Canada 2005) ${ }^{2}$ and the recent emergence of a number of studies on the health of immigrants in Canada there is a dearth of research on the health consequences to immigrant caregivers except for a few qualitative studies (Meadows, Thurston, and Melton 2001; Neufeld, et al. 2002). ${ }^{3}$ These studies have found that immigrant family caregivers tend to provide care to their relatives and friends out of love and out of feeling of giving back something (termed as "reciprocity" in this study) despite their own deteriorating health. Such strong feeling of reciprocity may impact the health of immigrant caregivers who may have already been the victims of "double jeopardy," disadvantaged by being informal caregivers on one hand and disadvantaged by being immigrants on the other. This study aims to investigate the double jeopardy hypothesis, whether "immigrant status" affects the health of family caregivers as a result of giving care to older adults in Canada and whether reciprocity has any role to play in the health impact to caregivers.

\section{Background}

Older adults being cared for by their family and community is widely accepted in Canada (Canadian Caregiver Coalition 2002: 1). In 2002, 1 in 5 Canadians who were aged 45 and over provided care to family or friends (Cranswick 2003). Estimates indicate that family caregivers provide more than $80 \%$ of all the care needed by individuals with long term health problems (Government of Canada 2006).

According to the 1996 General Social Survey (GSS), most caregivers were women, 30-59 years of age, educated, employed full-time, and married; had no children under age 15; urban based; lived in the neighbourhood of the care receivers; were an adult child of the care receiver; cared for a multiple number of receivers for more than two years; and were secondary caregivers (Fast and Keating 2001). Among the older adults aged 65 and over, $32 \%$ of women and $21 \%$ of men reported of receiving care due to long term health problems (Cranswick 2003). Recently, the Alberta Seniors and Community Supports (2008) reported that $90 \%$ of retirees wanted to live in their own homes during their senior years. The report also revealed that finding caregivers and household support to enable older adults to remain in their home was one of the most important issues faced by the older adults.

One cannot neglect health consequences to family caregivers given the fact that an estimated one million older adult Canadians received informal care in their home or community because of long-term health problems in 2002 (Cranswick 2003). Most studies (Grunfeld et al. 1997; Fast et al. 1999; NavaieWaliser et al. 2002) on older adult caregiving support the findings that long-term informal caregiving results in emotional and physical illness to caregivers. 
When the demand for caregiving escalates and caregiving stress increases, family caregivers report various health problems (Fast et al. 1999). Increased risk of poor health outcomes of caregivers is associated with race, advanced age, employment status, and inadequate social support (Navaie-Waliser et al. 2002).

Family caregivers are known to be motivated by a deeper commitment to the care receiver (Grunfeld et al. 1997). Such commitment, however, does not protect caregivers from the health consequences of caregiving. Despite the consequences of caregiving, most caregivers perceive providing care to their loved ones as rewarding (Heru, Ryan and Iqbal 2004) and worthwhile (Thomas et al. 2004). Also, caregivers have reported that they provide care out of love and responsibility (Heru et al. 2004). Most caregivers feel the reciprocity of giving something back to the care receiver. Such feelings may motivate caregivers to provide quality care but excessive feelings of reciprocity on the other hand may make them overwork and, consequently, may make them vulnerable to illness.

\section{Double Jeopardy Hypothesis}

It is well known that family caregivers pay an emotional and physical price as a consequence of caring for older adults with long-term illnesses (Keating et al. 1999; Fast et al. 1999; Fast and Keating 2001). The physical consequences of caregiving include physical strain and decline in general health status as the hidden costs of informal care (Fast et al. 1999).

Family caregiving to older adult patients, especially if the patients have dementia, is a demanding responsibility that might affect the health of caregivers, regardless of the immigration status of the caregivers. Nevertheless, immigrants face many political, social, and economic challenges in their new country. The health of immigrant caregivers may be affected more adversely than that of non-immigrants, due to the challenges of finding suitable jobs, language barriers, adaptational difficulties, inadequate housing, less social support, fewer care networks, discrimination, anxiety, and the loneliness that immigrants are likely to face in Canada (Harvey, Siu, and Reil 1999; Lai 2000; Newbold and Danforth 2003; Spitzer et al., 2003; Ng, Northcott, and Abu-Laban 2004; Oxman-Martinez et al. 2005). Correspondingly, immigrant caregivers may be the victims of "double jeopardy," being immigrants and becoming caregivers at the same time. In addition, feeling of reciprocity by these caregivers may play a significant role on their own health. There is evidence that immigrant women emphasize the importance of commitments to their family members rather than to their own well-being (Meadows et al. 2001) and they provide care to their loved ones regardless of their own weak health condition (Neufeld et al. 2002).

CSP 2010, 37.1-2: 107-124 
Whether living in a nuclear family or an extended one, adult children of immigrants still feel strong obligations towards their parents and grandparents (Kobayashi et al. 2005). Thus, institutionalizing older adults may be the last resort for most immigrant families (Assanand et al. 2005; Yue 2005). It implies that reciprocity could be a cultural phenomenon that people of various cultural backgrounds have been practicing from generation to generation. Immigrants bring such cultures when they enter Canada. Such feelings of reciprocity among immigrant caregivers may make them less stressed out than those who do not feel strong reciprocity. Nevertheless, too much feeling of reciprocity and consequently, caregiving without considering one's own well being may make these caregivers vulnerable to poor health. The feelings of reciprocity and the immigrant status of caregivers may have strong effect on the health of family caregivers.

The "double jeopardy" hypothesis serves as the framework for this study, which is based on the theory that the health of a certain population is impacted adversely in two ways: because of aging (or being female) and experiencing the additional burden of being a member of a minority group. For this study, the double jeopardy is being immigrant and being caregiver simultaneously. In the past, studies on the double jeopardy thesis of older adults and minority status showed unequivocal results (Dowd and Bengtson 1978; Penning 1983; Chan 1983; Rosenthal 1983 and 1986). Dowd and Bengtson (1978) analyzed the Los Angeles County data on Blacks, Mexican Americans, and Whites of the 45 to 74 years age group. They found support for the "double jeopardy" hypothesis on self-assessed health of minority older adults. Penning (1983) discovered a similar result. Chan (1983) acknowledged the "double jeopardy" situation of a group of senior Chinese women living in Montreal Chinatown on a study of these women's coping strategy for fighting their loneliness and opting out for independent lifestyle. These women faced double jeopardy of being old and having conflict with their Canadian-born sons and daughters-in-law living a western lifestyle.

The minority population studied by these researchers were not caregivers. In this study the theory of double jeopardy is applied to immigrant caregivers in relation to older adults with long-term health problems. The main purpose is to examine whether being caregivers and having immigrant status leads to a situation of becoming victims of "double jeopardy." We will also analyze the impact of reciprocity on the health of immigrant caregivers, for example, analyze whether reciprocity interacts with "immigrant status" in affecting the health outcomes of family caregivers. 


\section{Data and Methods}

Data from the General Social Survey (GSS) 2002, Cycle 16 were analyzed to investigate the health consequences of informal caregiving experienced by caregivers - immigrant caregivers in particular. The data collected from all over Canada excluded the Yukon, Nunavut, and the Northwest Territories. A total of 24,870 respondents aged 45 years and over were interviewed by telephone with a response rate of more than $86 \%$ (Statistics Canada, 2003a). Full-time residents of institutions were excluded.

\section{Sampling, Dependent Variable, and Independent Variables}

For this study, a sub-sample of caregivers was selected from the original data file. The respondents were persons who provided informal care to older adults (65 years of age and over) with a long-term health condition. The sub-sample contained 3501 cases, of which $16.3 \% \quad(n=570)$ were immigrant family caregivers and $83.7 \%(n=2931)$ were non-immigrant family caregivers.

Besides a descriptive analysis, two logistic regression analyses were executed. The dependent variable for this study is caregiver's health affected or not due to caregiving. The question asked was, "Looking back over the past 12 months, has assisting persons over the age of 65 caused you ... your health to be affected?" A dummy variable was created by recoding "health affected" as 1 and "not affected" as $0 .{ }^{4}$ Immigrant versus non-immigrant status variable was derived from the question "born in Canada or elsewhere." Reciprocity variable was derived from the question "How often do you...feel that by helping others, you simply give back what you have received from them?" Other variables included in the analysis were: age, sex, place of residence (rural versus urban), household size, children (0-14 years of age) present in the household, language often spoken at home, marital status, education level, satisfaction with the frequency of contact with relatives (relatives other than care receiver), life in general stressful, no time for self, change in sleeping pattern, and providing personal care. ${ }^{5}$ These variables were treated as "control" variables. See Appendix for the specification of variables.

Several weight variables were available in the data, including bootstrap weights (See Phillips, Statistics Canada, Catalogue No. 12-002-XIE, 2004 for details on bootstrap weights). To adjust for over-sampling in small population provinces and for the higher possibility of people living in smaller households being selected to participate than those living in larger households, Statistics Canada recommends using the basic weighting factor at the person level for all estimates (Statistics Canada 2003b). Therefore, the specified weighting factor at personal level was used before analyzing the data. SPSS software version 13 was used for analysis.

CSP 2010, 37.1-2: 107-124 
One of the limitations of using the GSS 2002 Cycle 16 data was that it includes only those who were aged 45 and older, which excludes younger caregivers. Also, the figures that appear in the GSS 2002 Cycle 16 data were estimates based on a sample collected from a small fraction of the population (roughly one person in 448 of the population 45 years of age and over), therefore there is possibility of some sampling error (Statistics Canada 2003a). Besides this survey being a "self-reported" or "self-perceived" one (meaning that the responses of the survey participants may depend on how they perceive a certain factor, say, their health), the question of health consequences to caregivers was dichotomous in nature, leaving the respondents without a choice other than to respond "yes or no," which may not be as strong a response as ordinal categories (for example, ranging from 'extremely' to 'not at all'). ${ }^{6}$ The dichotomy also concealed the major or minor impact on health of caregivers. Moreover, the outcome question did not show directionality of health impact. Nevertheless, the explanation of "health affected" as adverse effect to caregivers by the survey interviewer to the respondent before asking this particular question does overcome this particular limitation. Furthermore, cultural variables were not included in the GSS 2002 Cycle 16 survey except for the country of birth variable. ${ }^{7,8}$

\section{Results}

\section{Descriptive Analysis}

Among the immigrant caregivers, $16.1 \%$ said that their health was affected because of caring for older adults, whereas $13.6 \%$ non-immigrant caregivers said the same (Table 1). Some $18.6 \%$ of immigrant family caregivers were older adults (65 years of age and over) themselves compared with $14.6 \%$ of nonimmigrant caregivers in that age group. A significantly higher proportion of non-immigrants lived in rural areas, spoke English or French at home, and had to change sleep pattern to adjust with the caregiving tasks than did immigrant caregivers. A significantly higher proportion of immigrants lived with young children. Similarly, a significantly higher proportions of immigrant caregivers lived in larger families, were university graduates and reported life 'not at all' stressful than those of non-immigrant caregivers and a significantly higher proportion of non-immigrant caregivers reported having a 'very' stressful life and 'always' feeling reciprocity compared to those of immigrant caregivers.

CSP 2010, 37.1-2: 107-124 
Table 1

Characteristics of Family Caregivers by Immigration Status, Canada: 2002 ${ }^{\mathrm{a}}$

\begin{tabular}{|c|c|c|c|}
\hline \multirow{3}{*}{ Variables } & \multicolumn{2}{|c|}{ Proportion } & \multirow{3}{*}{ p-value ${ }^{b}$} \\
\hline & \multirow{2}{*}{$\begin{array}{c}\text { Immigrants } \\
\qquad(n=570)\end{array}$} & \multirow{2}{*}{$\begin{array}{c}\text { Non-Immigrants } \\
(n=2931)\end{array}$} & \\
\hline & & & \\
\hline Age: & & & 0.005 \\
\hline 45-64 years & 81.4 & 85.4 & \\
\hline $65+$ years & 18.6 & 14.6 & \\
\hline Sex: & & & 0.071 \\
\hline Male & 50.5 & 46.4 & \\
\hline Female & 49.5 & 53.6 & \\
\hline Place of Residence: & & & 0.000 \\
\hline Urban & 87.9 & 74.1 & \\
\hline Rural & 12.1 & 25.9 & \\
\hline Household Size: & & & 0.000 \\
\hline 1 member & 9.7 & 14.1 & \\
\hline 2 members & 39.9 & 47.8 & \\
\hline 3-6 members & 50.4 & 38.1 & \\
\hline Presence of Children ( $0-14$ years) in the Household & 16.0 & 11.9 & 0.009 \\
\hline Language Spoken at Home (English or French) & 78.2 & 98.9 & 0.000 \\
\hline Marital Status: & & & 0.358 \\
\hline Married & 79.0 & 77.0 & \\
\hline Single & 5.6 & 7.2 & \\
\hline Divorced + Separated + Widowed & 15.4 & 15.8 & \\
\hline Education Level: & & & 0.000 \\
\hline University Graduates & 34.0 & 22.0 & \\
\hline High School or Some College & 62.3 & 73.3 & \\
\hline Elementary or No Schooling & 3.7 & 4.7 & \\
\hline Relative Contact: & & & 0.058 \\
\hline Very Satisfied & 28.7 & 28.9 & \\
\hline Satisfied & 58.9 & 61.9 & \\
\hline Dissatisfied & 12.4 & 9.2 & \\
\hline Life in General Stressful: & & & 0.005 \\
\hline Very & 8.2 & 12.0 & \\
\hline Somewhat & 75.3 & 75.2 & \\
\hline Not at all & 16.5 & 12.8 & \\
\hline No Time for Self: & & & 0.952 \\
\hline Rarely & 66.7 & 67.3 & \\
\hline Sometimes & 24.9 & 24.6 & \\
\hline Always & 8.4 & 8.1 & \\
\hline Reciprocity: & & & 0.005 \\
\hline Rarely & 22.6 & 20.6 & \\
\hline Sometimes & 29.5 & 24.3 & \\
\hline Always & 47.9 & 55.1 & \\
\hline Had to Change Sleep Pattern & 11.8 & 14.9 & 0.049 \\
\hline Provided Personal Care & 24.2 & 24.1 & 0.953 \\
\hline Health Affected because of Informal Caregiving & 16.1 & 13.6 & 0.110 \\
\hline
\end{tabular}

a Source: Computed from the Canadian General Social Survey 2002, Cycle 16 data.

b-values based on $\chi^{2}$-Test 


\section{Logistic Regression Analysis}

Table 2 (Model 1) shows that immigrant caregivers were more likely to report a health consequence than non-immigrant caregivers when the effects of selected variables, including reciprocity, were held constant. However, the result was not significant at that point. When an interaction term of reciprocity and immigrant status was added in the model (Table 2, Model 2), the interaction effect suggested that immigrant caregivers who 'sometimes' or 'always' felt reciprocity were less likely to report a health consequence than those who 'rarely' felt reciprocity. When the interaction effect of reciprocity and immigrant status was held constant, the odds of status revealed that immigrant family caregivers were almost 3 times more likely to say that their health was affected as a result of caregiving than their non-immigrant counterparts even when the effects of selected demographic, socio-economic, and circumstantial variables were controlled. Thus, reciprocity interacts with immigrant status to impact immigrant caregivers' health. Similarly, caregivers who 'sometimes' or 'always' felt reciprocity were more likely to report a health impact than those caregivers who 'rarely' felt that way.

Apart from immigrant status and reciprocity, being older, being female, living with young children, speaking a language other than English or French, and having lower level of education, all affected the health of caregivers. Frequency of contact with caregivers' relatives, life in general stressful, no time for themselves, sleep adjustments, and providing personal care also impacted the health of family caregivers.

\section{Conclusion}

This study has revealed that immigrant status of caregivers has negative impact on self-reported health of caregivers who care for older adults with long-term illnesses. The double jeopardy hypothesis, thus, is supported in the case of immigrant caregivers in Canada. Immigrant family caregivers indeed appear to be victims of being caregivers on one hand and being immigrants on the other. However, feeling of reciprocity played a major "moderator" role in their health impact.

Even though Canada is an increasingly multicultural society, the study of family caregiving among immigrants is in its infancy. It is important to understand the health consequences to immigrant caregivers and the factors that impact their health. Such understanding could help the development of culturefriendly health policies for an overall healthy Canada. Surveys designed to target immigrants and different cultural groups, and specifically caregivers, could lead to greater awareness of the health effects of family caregiving.

CSP 2010, 37.1-2: 107-124 
Table 2

Logistic Regression: Health Outcome among Caregivers, Canada: 2002

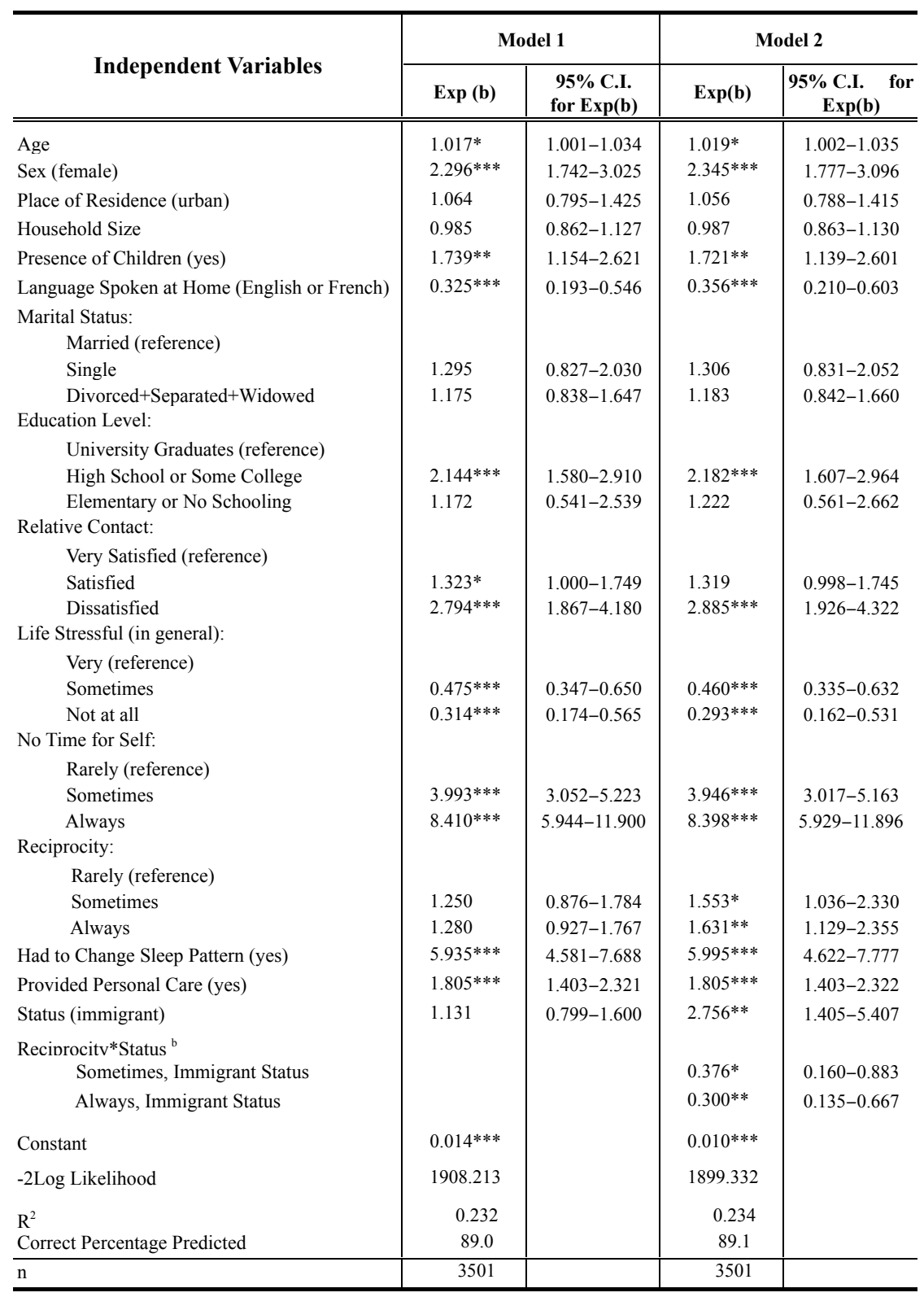

${ }^{a}$ Computed from the Canadian General Social Survey 2002, Cycle 16 data. ${ }^{* * *} \mathrm{p}<0.001 ; * * \mathrm{p}<0.01 ; * \mathrm{p}<0.05$.

${ }^{\mathrm{b}}$ Immigrant status versus non-immigrant status, (coded as immigrant $=1$, non-immigrant $=0$ ). 
The findings from this study have policy implications for increasing the quality of life of immigrant caregivers, as well as the quality of care being provided. If immigrant caregivers need to make tremendous adjustments in life and if their health is affected beyond what they can tolerate, the possible choice left for these overworked caregivers will be to institutionalize their loved ones. This might expose themselves to the risk of becoming care receivers themselves or even have to spend the rest of their lives in institutions themselves as a result of deteriorating health and stress due to caregiving. This could be a dilemma for immigrant caregivers: first whether to institutionalize their older family members or care for them at home; second, most immigrants may not be able to afford the cost of institutionalization, even if they feel compelled to do so. Any kind of external help or free respite care would help to ease the overloaded tasks of immigrant caregivers, which would eventually help in keeping them healthy. Furthermore, except for a few cities such as those in Ontario, culturally responsive health care and ethnic long-term care homes are still lacking in Canada (Anderson et al. 2005) similar to the situation two decades ago (Ujimoto 1987). Such limitations may create more discomfort and stress to immigrant caregivers, and thus influence their health; therefore, Canadian policy makers urgently need to find a way to resolve such issues.

As the population ages and diversifies with increasing number of immigrants from all over the world coming into Canada, policy makers will face more challenges in developing and providing policies appropriate for immigrant caregivers. Policy makers may benefit by consulting social scientists, healthcare providers, immigrant caregivers, and leaders from various communities, as well as care receivers for better understanding immigrant caregivers' challenges. Hyman (2001) discussed the importance of immigrant health and the need for direct funding toward the maintenance and promotion of immigrant health. From our findings, a similar suggestion for immigrant caregivers' health can be made. The importance of this research can benefit Canada by insuring that family caregivers, especially immigrant family caregivers, can get support - thus relieving governmental overall health costs. 


\section{Acknowledgements}

The initial data analysis for this research was completed at the Research Data Centre while the author was a post-doctoral fellow in the Department of Human Ecology, University of Alberta.

The author would like to thank Dr. Janet Fast of the Department of Human Ecology and Dr. Wayne McVey (Emeritus) of the Department of Sociology, University of Alberta for their comments and suggestions on the earlier version of this paper. The author would also like to thank the three anonymous reviewers for their invaluable comments. Responsibility for any errors rests with the author.

\section{End Notes}

1. Caregivers are family members or friends who provide both short term and ongoing care and assistance, without pay, to those in need of support due to physical, cognitive or mental health conditions (Canadian Caregiver Coalition 2003). These caregivers are often referred to as 'family caregivers' or 'informal caregivers.' For this study, 'family caregivers' and 'caregivers' are used interchangeably and the unpaid care provided by them is referred to as informal care.

2. Since 1997 most immigrants to Canada have come from non-European countries (Hyman 2001).

3. Gerontologists (Fast, Williamson, and Keating 1999) believe that when family caregivers care for their loved older adults who have long-term illnesses, the caregivers' quality of life including their physical and emotional well-being declines, among other things. Physical well being here means physical health. The decline of physical health of caregivers as a consequence of caring for older adults is termed as "health consequences" in this paper.

4. It should be noted that the health consequences or health outcomes mentioned in our findings and discussions are in fact "self-reported" or "self-perceived" health outcomes reported by caregivers.

5. Some scholars may argue that "change in sleep pattern" should be treated as an outcome (dependent) variable of caregiving. While it is a valid argument, this variable was included in Logistic regression equation as a control variable so that the effects of immigrant status, reciprocity, and 
their interaction on self-reported health consequence could be isolated from the confounding effect of "change in sleep pattern" variable on the dependent variable because change in sleep pattern may affect the health of caregivers.

6. Future surveys should take this dichotomy of dependent variable into consideration and subsequently obtain a stronger measure of health consequences of caregiving.

7. At least the sample size for immigrants should be large enough in future national surveys so that research on health impacts of caregiving relevant to specific immigrant groups (West European, South Asian, East Asian, Latino, and African), if not to each cultural group, could be conducted. The importance of separating immigrants by various regions and countries of origin in immigrant-health-related studies has been acknowledged by previous researchers (Gee, Kobayashi, and Prus 2004) as well.

8. Given the limitations of GSS Cycle 16 survey, future researchers should collect primary data on immigrant caregivers by their cultural background, as Leduc and Proulx (2004) did for their qualitative study of health care use by recent immigrants.

\section{References}

Alberta Seniors and Community Supports. 2008. Findings Report. Edmonton, Alberta, Canada

Anderson, J. M., S. R. Kirkham, N. Waxler-Morrison, C. Herbert, M. Murphy and E. Richardson. 2005. "Conclusion: Delivering culturally responsive health care," in N. Waxler-Morrison, J.M. Anderson, E. Richardson, \& N.A. Chambers (Eds.), Cross-cultural Caring: A Handbook for Health Professionals. Vancouver, Canada: UBC Press. Pp. 323-352.

Assanand, S., M. Dias, E. Richardson, N. A. Chambers and N. WaxlerMorrison. 2005. "People of South Asian descent," in N. WaxlerMorrison, J.M. Anderson, E. Richardson and N.A. Chambers (Eds.), Cross-cultural Caring: A Handbook for Health Professionals. Vancouver, Canada: UBC Press. Pp. 197-246. 
Campbell, J., G. Bruhn and S. Lilley. 1998. Caregivers' support needs: Insights from the experiences of women providing care in rural Nova Scotia. Halifax Canada: Maritime Centre of Excellence for Women's Health, Dalhousie University.

Canadian Caregiver Coalition (CCC). 2002. "Calling for a national caregiving policy: A prerequisite for providing home and community care." $C C C$ Policy Paper Series Number 1. Ottawa: CCC-CCAN.

Canadian Caregiver Coalition (CCC). 2003. "Caring together: Caregiver recognition is sound social policy." CCC Policy Paper Series Number 2. Ottawa: CCC-CCAN.

Chan, K. B. 1983. "Coping with aging and managing self-identity: The social world of the elderly Chinese women." Canadian Ethnic Studies 15(3): 36-50.

Cox, C. and A. Monk. 1993. "Hispanic culture and family care of Alzheimer's patients." Health and Social Work 18(2): 92-100.

Cranswick, K. 2003. General Social Survey Cycle 16: Caring for an Aging Society. Ottawa: Statistics Canada, Catalogue no. 89-582-XIE.

Dowd, James J. and Vern L. Bengtson. 1978. "Aging in minority populations: An examination of the double jeopardy hypothesis." Journal of Gerontology 33(3): 427-436.

Fast, J. E. and N. C. Keating. 2001 Informal caregiving in Canada: A snapshot. Report of Research on Aging, Policies, and Practices (RAPP) to the Health Services Division, Health Policy and Communications Branch, Health Canada.

Fast, J. E., D. L. Williamson and N. C. Keating. 1999. "The hidden costs of informal elder care." Journal of Family and Economic Issues 20(3): 301-326.

Gee, E. M., K. M. Kobayashi and S. G. Prus. 2004. "Examining the healthy immigrant effect in mid- to later life: Findings from the Canadian Community Health Survey." Canadian Journal on Aging, Supplement 23: S55-S63.

CSP 2010, 37.1-2: 107-124 
Health Consequences to Immigrant Family Caregivers in Canada

Government of Canada. 2006. Caregivers: Unpaid caregivers in Canada. Retrieved on June 6, 2006 from Ottawa: Social Development Canada. http://www.hrsdc.gc.ca/en/cs/comm/sd/caregivers.shtml.

Grunfeld, E., R. Glossop, I. McDowell and C. Danbrook. 1997. "Caring for older adults people at home: The consequences to caregivers." Canadian Medical Association Journal 157(8): 1101-1105.

Harvey, E. B., B. Siu and K. D. V. Reil. 1999. "Ethno-cultural groups, period of immigration and socioeconomic situations." Canadian Ethnic Studies 31(3): 95-103.

Hennessy, C. H. and R. John. 1996. "American Indian family caregivers' perceptions of burden and needed support services." Journal of Applied Gerontology 15: 275-293.

Heru, A. M., C. E. Ryan and A. Iqbal. 2004. "Family functioning in the caregivers of patients with dementia." International Journal of Geriatric Psychiatry 19(6): 533-537.

Hyman, I. 2001. "Immigration and health." Health Policy Workshop Paper Series, Number 01-05. Ottawa: Health Canada.

Keating, N., J. Fast, J. Frederick, J. K. Cranswick and C. Perrier. 1999. Eldercare in Canada: Context, content and consequences. Ottawa, Canada: Statistics Canada, Housing, Family and Social Statistics Division.

Kobayashi, K., T. Okabe, K. Takahashi and E. Richardson. 2005. "People of Japanese descent," in N. Waxler-Morrison, J. M. Anderson, E. Richardson and N.A. Chambers (eds.), Cross-cultural caring: A handbook for health professionals. Vancouver, Canada: UBC Press. Pp. 163-196.

Kosmala, K. and I. Kloszewska. 2004. "The burden of providing care for Alzheimer's disease patients in Poland." International Journal of Geriatric Psychiatry 19: 191-193.

Lai, Daniel W. L. 2000. "Depression among the elderly Chinese in Canada." Canadian Journal on Aging 19(3): 409-429.

Leduc, N. and M. Proulx. 2004. "Pattern of health services utilization by recent immigrants." Journal of Immigrant Health 6(1): 15-27.

CSP 2010, 37.1-2: 107-124 
Meadows, L. M., W. E. Thurston and C. Melton. 2001. "Immigrant women's health.” Social Science \& Medicine 52: 1451-1458.

Navaie-Waliser, M., P. H. Feldman, D. A. Gould, C. Levine, A. N. Kuerbis and K. Donelan. 2002. "When the caregiver needs care: The plight of vulnerable caregivers." American Journal of Public Health 92(3): 409-413.

Neufeld, A., Harrison, M. J., Stewart, M. J., Hughes, K. D. and D. Spitzer. 2002. "Immigrant women: Making connections to community resources for support in family caregiving." Qualitative Health Research 12(6): 751-768.

Newbold, B. K. and J. Danforth. 2003. "Health status and Canada's immigrant population." Social Science and Medicine 57: 1981-1995.

Ng, C. F., H. C. Northcott and S. M. Abu-Laban. 2004. The Experiences of South Asian Immigrant Older adults Living in Edmonton, Alberta: Report to the Community. Edmonton, Canada: Alberta Centre on Aging, University of Alberta.

Oxman-Martinez, J., J. Hanley, L. Lach, N. Khanlou, S. Weerasinghe and V. Agnew. 2005. "Intersection of Canadian policy parameters affecting women with precarious immigration status: A baseline for understanding barrier to health." Journal of Immigrant Health 7(4): 247-258.

Penning, Margaret J. 1983. "Multiple jeopardy: Age, sex, and ethnic variations." Canadian Ethnic Studies 15(3): 81-105.

Pinquart, M. and S. Sörensen. 2003. "Differences between caregivers and noncaregivers in psychological health and physical health: a metaanalysis." Psychology and Aging 18(2): 250-263.

Policy Forum on Unpaid Caregiving. 2003. Economic security for caregivers: A policy development process to better support unpaid caregivers (Summary Report). Ottawa: The Canadian Association for Community Living (CACL) in partnership with the Canadian Caregiver Coalition (CCC-CCAN).

Rosenthal, Carolyn J. 1983. "Aging, ethnicity and the family: Beyond the modernization thesis." Canadian Ethnic Studies 15(3): 1-16. 
Health Consequences to Immigrant Family Caregivers in Canada

Rosenthal, Carolyn J. 1986. "Family supports in later life: Does ethnicity make a difference?" The Gerontologist 26(1): 19-24.

Spitzer, D., A. Neufeld, M. Harrison, K. Hughes and M. Stewart. 2003. "Caregiving in transnational context 'My wings have been cut; where can I fly?"” Gender and Society 17(2): 267-286.

Statistics Canada. 2003a. 2002 General Social Survey Cycle 16: Aging and Social Support Tables. Ottawa, Statistics Canada: Housing, Family and Social Statistics Division. Catalogue No. 89-583-XIE.

Statistics Canada. 2003b. General Social Survey (GSS), Social Support and Aging, detailed information for 2002 (Cycle 16), Data Release, September 2, 2003. Retrieved on July 5, 2006 from http://www.statcan.ca/cgibin/imdb/p2SV.pl?Function $=$ getSurvey \&SDDS $=4502 \& l a n g=e n \& d b=I$ MDB\&dbg $=$ f $\&$ adm $=8 \&$ dis $=2$

Statistics Canada. 2005. Proportion of foreign-born population by province and territory (1991 to 2001 Censuses). Retrieved on December 12, 2006 from http://www40.statcan.ca/101/cst01/demo46a.htm

Stockmann, N. 2000. Understanding Chinese Society. Boston, U.S.A.: Polity Press.

Thomas, P., P. Ingrand, F. Lalloue, C. Hazif-Thomas, R. Billion, F. Viéban and J. Clément. 2004. "Reasons of informal caregivers for institutionalizing dementia patients previously living at home: The Pixel Study.” International Journal of Geriatric Psychiatry 19(2): 127-135.

Ujimoto, K.V. 1987. "The ethnic dimension of aging in Canada," in V.W. Marshall (Ed.), Aging in Canada: Social perspectives (Second Edition) Ontario, Canada: Fitzhenry \& Whiteside. Pp. 111-137.

Victorian Order of Nurses (VON). 2005. VON Canada caregiving program: An overview. Ottawa, Ontario: VON Canada.

Yue, K. K. 2005. "People of Chinese descent," in N. Waxler-Morrison, J. M. Anderson, E. Richardson and N. A. Chambers (Eds.), Cross-cultural caring: A handbook for health professionals. Vancouver, Canada: UBC Press. Pp. 59-93.

CSP 2010, 37.1-2: 107-124 


\section{Appendix}

Measurement and Specification of Variables for Logistic Regression Analysis, GSS Cycle 16, 2002

\begin{tabular}{|c|c|}
\hline Variables & Specification/Categories \\
\hline Age & Number of years \\
\hline Sex & Male (reference) or Female \\
\hline Place of Residence & Rural (reference) or Urban \\
\hline Household Size & Number of family members living in a household \\
\hline $\begin{array}{l}\text { Presence of Children less than } 14 \\
\text { years in the Household }\end{array}$ & $\begin{array}{l}\text { Presence } \\
\text { or Non-presence (reference) }\end{array}$ \\
\hline Language Spoken at Home & $\begin{array}{l}\text { English/French } \\
\text { or Other (reference) }\end{array}$ \\
\hline Marital Status & $\begin{array}{l}\text { Married (reference) } \\
\text { Single } \\
\text { Widowed/Divorced/Separated }\end{array}$ \\
\hline Education Level & $\begin{array}{l}\text { University graduate (reference) } \\
\text { High School/Some College } \\
\text { No School/elementary }\end{array}$ \\
\hline Satisfaction with Relative Contact & $\begin{array}{l}\text { Very Satisfied (reference) } \\
\text { Somewhat stressful } \\
\text { Not at all stressful }\end{array}$ \\
\hline Life in General Stressful & $\begin{array}{l}\text { Very stressful (reference) } \\
\text { Somewhat stressful } \\
\text { Not at all stressful }\end{array}$ \\
\hline No Time for Self & $\begin{array}{l}\text { Rarely feel "don't have enough time for self" (reference) } \\
\text { Sometimes feel "don't have enough time for self" } \\
\text { Always feel "don't have enough time for self" }\end{array}$ \\
\hline Reciprocity & $\begin{array}{l}\text { Rarely (reference) } \\
\text { Sometimes } \\
\text { Always }\end{array}$ \\
\hline $\begin{array}{l}\text { Had to Change Sleep Pattern } \\
\text { Provided Personal Care } \\
\text { Status }\end{array}$ & $\begin{array}{l}\text { Yes or No (reference) } \\
\text { Yes or No (reference) } \\
\text { Immigrant (born outside of Canada) } \\
\text { or Non-immigrants (born in Canada) (reference) }\end{array}$ \\
\hline
\end{tabular}

